\title{
Functionalization of Surfaces via Grinding Process - An Application for Crankshaft Manufacturing
}

\author{
Alex Camilli Bottene ${ }^{1}$, Almir Atoatte ${ }^{2}$ Eraldo Jannone da Silva ${ }^{1}$, João Fernando Gomes de \\ Oliveira ${ }^{1}$, Gustavo Pollettini Marcos ${ }^{1}$ \\ ${ }^{1}$ Universidade de São Paulo - EESC-USP \\ ${ }^{2}$ ThyssenKrupp - Metalúrgica Campo Limpo
}

E-mails: alex.bottene@ usp.br, almir.atoatte@thyssenkrupp.com, eraldojs@sc.usp.br, jfgo@sc.usp.br, gustavo_marcos@@hotmail.com

\begin{abstract}
The growing demand for lowering emissions leads to an effort to enhance internal combustion engines performance through new engineering solutions. The functionalization of surfaces applied to crankshaft bearings represents one of the possible solutions to achieve this balance. In this method, a micrometric tailored texture is produced on the surface to optimize the fluid dynamics in the bearing, increase load capacity, bearing stability and lower general operational losses. The better performance allows downsizing these bearings, enabling a possible significant reduction on weight and fuel consumption. The project is a partnership between the School of Engineering of Sao Carlos (EESC-USP) and the ThyssenKrupp Company. It applies a new process developed in cooperation with the Laboratory for Advanced Process and Sustainability (LAPRAS). In the proposed methodology, the desired texture is inscribed in the crankshaft bearings during the grinding process, with same precision and quality associated with this vastly applied manufacturing process. For operational evaluation, tribological tests will be carried out and finally in an instrumented engine evaluation will be performed.
\end{abstract}

\section{INTRODUCTION}

The growing demands for less fuel consumption pressure automotive industry to develop technologies in order to make more efficient and robust vehicles. The California 80in50 is an example of such scenario. The executive standard established by the state government aims in 2050 to have only $80 \%$ of the greenhouse gas (GHG) emission of those recorded in 1990 related to transportation emissions [1]. In another study, the baseline for the amount of energy directed related to road vehicles transport represent the great amount of $75 \%$, transferring the mass impact for cars and trucks in general [2]. The European standard for the reduction of GHG was also designed in order to pressure the European Automotive Manufacturers Association (ACEA) for mass reduction over the time [2]. A newer example of same pressure can be found in the Chinese and Brazilian regulations for less oil consumption related to road transportation. In 2009 the Chinese vehicle sales rate had overcome US standards, encouraging great efforts for support the reduction in fuel consumption in the country [3]. The Brazilian INOVAR-AUTO is the national program to impose the fuel reduction in the next years for the Brazilian automotive industry [4]. 
Many technologies are being developed in order to allow the automotive industry to achieve the demands, however many still lack of enough maturity and/or financial sustainability to be applied. One example is the alternative fuels vehicles (AFV). AFVs represents' one of the main possible breakthrough for reducing GHG, however technology for these still have market barriers and the final expected results are discussable [5]. This is also presented by [6]. A more complex and systematic analysis is used in order to evaluate possible advances in the car manufacturing companies for achieving better results. The methodology in based in the Life Cycle Assessment (LCA) guidelines. The author based the analysis in the main underdevelopment research to achieve results in less fuel consumption and better performance. The result indicated that less weight and more efficient power train are the main strategy to achieve enhanced results. For [10], the total energy consumption associated only with driving represents $71 \%$ of the energy in entire life cycle. Both results encourage development to reduce the impact of the fuel consumption itself, the leading impact.

The same results can be found in [7] and [8]. Both studies presented the direct correlation between fuel consumption and the energy loss due to friction. Engines parts, transmission and traction represent some of the main power train components. For [7], in passengers' cars one third of the fuel energy is used to overcome friction in those parts. Enlarging the analysis for world fuel consumption values, the amount of fuel that is loss in the car life cycle is highly representative, 280,00 million liters in just one year. Such numbers represents how investing in new fuel sources are just one of the possible backgrounds to achieve future limits of fuel consumption.

For [8], particularly the engine itself represents the higher losses of energy from fuel consumption, around $48 \%$ of the energy. Friction represents around $11 \%$ of the total losses in light-duty vehicle, a representative number with direct affect in the car efficiency. Many opportunities can be found to enhance the tribology in the moving parts for reducing friction and wear. Figure 1 represents some of such possibilities.

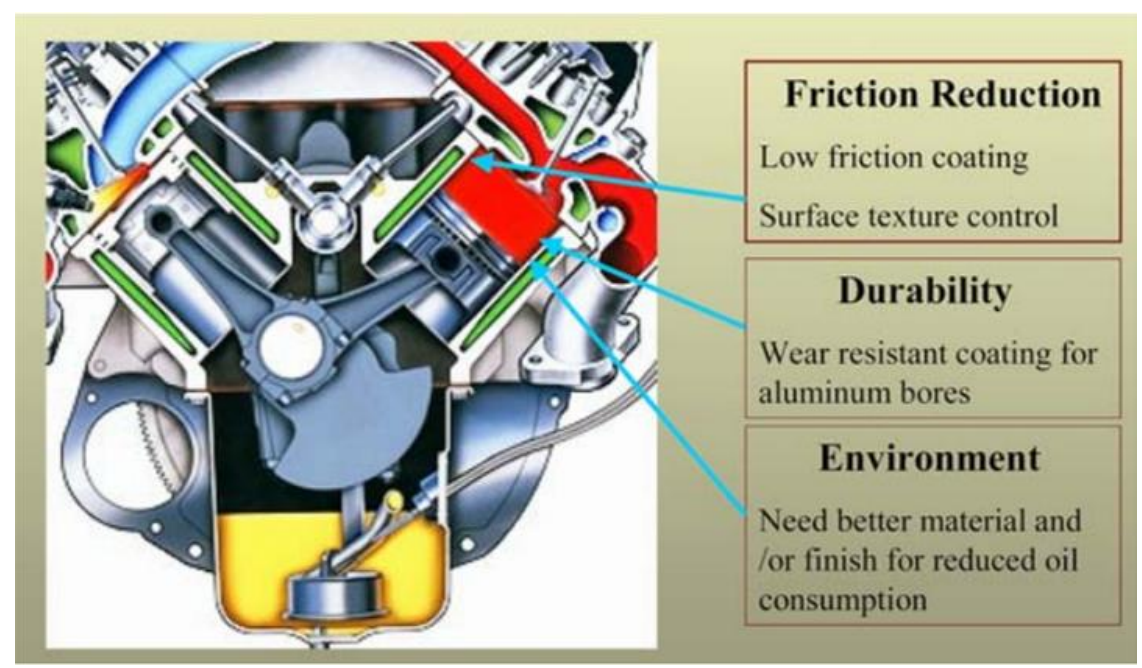

Figure 1 - Possibilities for tribology enhancement in engine moving parts [8].

For [9], the friction losses represent around $15 \%$ of the total energy supplied to the engines. Many engines parts can be redesign to reduce friction losses and inertia mass. Surface functionalization by means of tribological coating is presented as a suitable option to enhance 
the engine performance. More particular, nano-structured coatings imply more benefits. However, the author also presents the still underdevelopment aspects, such as: industrialization of the coating process and the design of the new coatings.

In this work it is discussed technologies and manufacturing process used for surface functionalization, more particularly applied to engine parts under friction losses. A new method is presented to produce tailored surfaces via grinding process. The patented method aims to engrave surfaces for better lubricant dynamic behavior, less friction and higher load performance.

\section{CURRENT SCENARIO FOR SURFACE FUNCTIONALIZATION}

Surface functionalization represents methodologies for enhance surface performance. For [11], many different function proprieties are direct associated with the surface, such as: tribological, mechanical, optical and others. A literature review is presented in the work, basically classified in 4 groups: adding, removing and moving material, and self-forming [11]. For the scenario of surfaces engineering applied for engine parts, most work is present using special coatings and removing materials for pattern generation.

The main materials used for engine parts manufacturing in presented in [12]. The author also present the associated coatings developed to be applied in these new materials. Less friction and wear are associated with the use of these special coatings. One example of application and the results obtained in presented in [13], were a particular coating was applied in engine cylinders, pistons and rings.

Another methodology for surface functionalization is the removing material process. For [14], the most applied method in recent research papers is the laser texturing. The processes uses laser precision energy to create dimples or oil pockets with micro-scale depth to enlarge load capacity, wear resistance and improve friction coefficient. The cavities serve as microhydrodynamic bearing, micro-reservoirs and micro-trap for particles and chips [14]. The author tried to achieve these results producing the texturing with a different process, the burnishing technique. References [15] and [16] used laser texturing to produce semi-sphere dimples in engines parts under friction and lubrications conditions. Results encourage the use of such high-precision material removing process, however the high cost and time associated represent a barrier for industrial applications.

\section{CURRENT SCENARIO FOR CRANKSHAFT MANUFACTURING}

Crankshafts conventional manufacturing operations are subject to rough machining (turning and milling), semi-finishing operations (grinding) and final finishing (lapping). Finishing operations are required for surfaces with mirror-like characteristics and precise geometrical tolerances. The surface in crankshaft operational behavior represents an important trend to define the bearing lubrication regime in service, and consequently, affects the fatigue and lifetime of the component.

Furthermore, recent advances in tribology engineering encourage the application of micro patterned surfaces for enhancement of lubrication properties. Studies, from [11] to [16], represent some of the literature results regarding in service optimization for hydrodynamic effects, particularly, improving the hydrodynamic lift and pressure distribution along the 
moving surfaces. These patterns behave as micro oil bearings for controlling the flow of the lubricant to critical regions of the bearing surface and providing micro chambers for chips and particles protection.

Laser melting and laser ablation techniques have been successfully used in order to generate micro patterns on bearing surfaces, obtaining substantial improvement of lubrication characteristics. However, these processes have intrinsic limitations, such as: longer time cycles and generation of bur and tensile surface residual stress during the process, which requires post-processing.

In this context this work present a method to achieve compatible and improved laser texturing results using the grinding as the material removing process. Therefore, less cost is associated with the texturing stage, producing the patterns during the normal crankshaft grinding cycle. Crankshafts was selected as a target product for surface texturing due its potential of reduce friction loss and enhance hydrodynamic performance through the uses of mains and pins textured bearing surfaces. The motivational goals are enhance hydrodynamic behavior, consequently reduce the part inertia and fuel consumption in combustion engines.

\section{MOTIVATION}

The "ThyssenKrupp Forging Group" Campo Limpo Paulista, have years of experience in the development and production of crankshafts and engine components. The constant pressure to reduce emissions has led the automotive industry to seek engineering solutions that improve the performance of internal combustion engines. One possibility to meet the new requirements is the introduction of textures on the surface of the crankshaft bearings, so that they operate with lower fuel consumption and higher load capacity, allowing downsizing of engines. The 3-year project, conducted in partnership with the Laboratory of Advanced Process and Sustainability (LAPRAS) of São Carlos - School of Engineering (EESC) - University of São Paulo (USP), seeks to develop such textures and apply them in crankshafts through a process developed by the (LAPRAS-EESC). Patterns are transferred to the bearing surface during grinding. The performance of textured components will be evaluated in simplified tribological and engine tests. Project details are presented below.

\section{THE PROPOSAL - FUNCTIONALIZATION OF SURFACES VIA GRINDING PROCESS}

The grinding process is already commonly applied in the automotive industry to precise control the dimensional and geometry of metals parts as well as surface parameters. Dressing is the operation for controlling the cutting tool surface. Periodically, small volume is removed from the wheel periphery with the dressing tool for adjusting wheel sharpness and geometry. Eventual vibrations and lack of precision during the dressing, unwanted patterns are created in the wheel surface. During the grinding stage, those patters affect the part final results, inscribing wave textures in the contact area of wheel and part. Those results could be found in cylindrical grinding of engine valves. The desire in controlling the shape of those patterns encourages the development of a methodology to use the wheel topography as the engraving tool.

The method uses an electro-mechanical device for precisely control the dressing operation.. The objective is to dynamically change the dressing depth for generating textures on the wheel surface that can be transferred to the part during the grinding. Software is required to 
generate signals based on the desired texture to be generated. In Figure 2, the method is presented. Full details of the methodology can be found in [17] and [18].

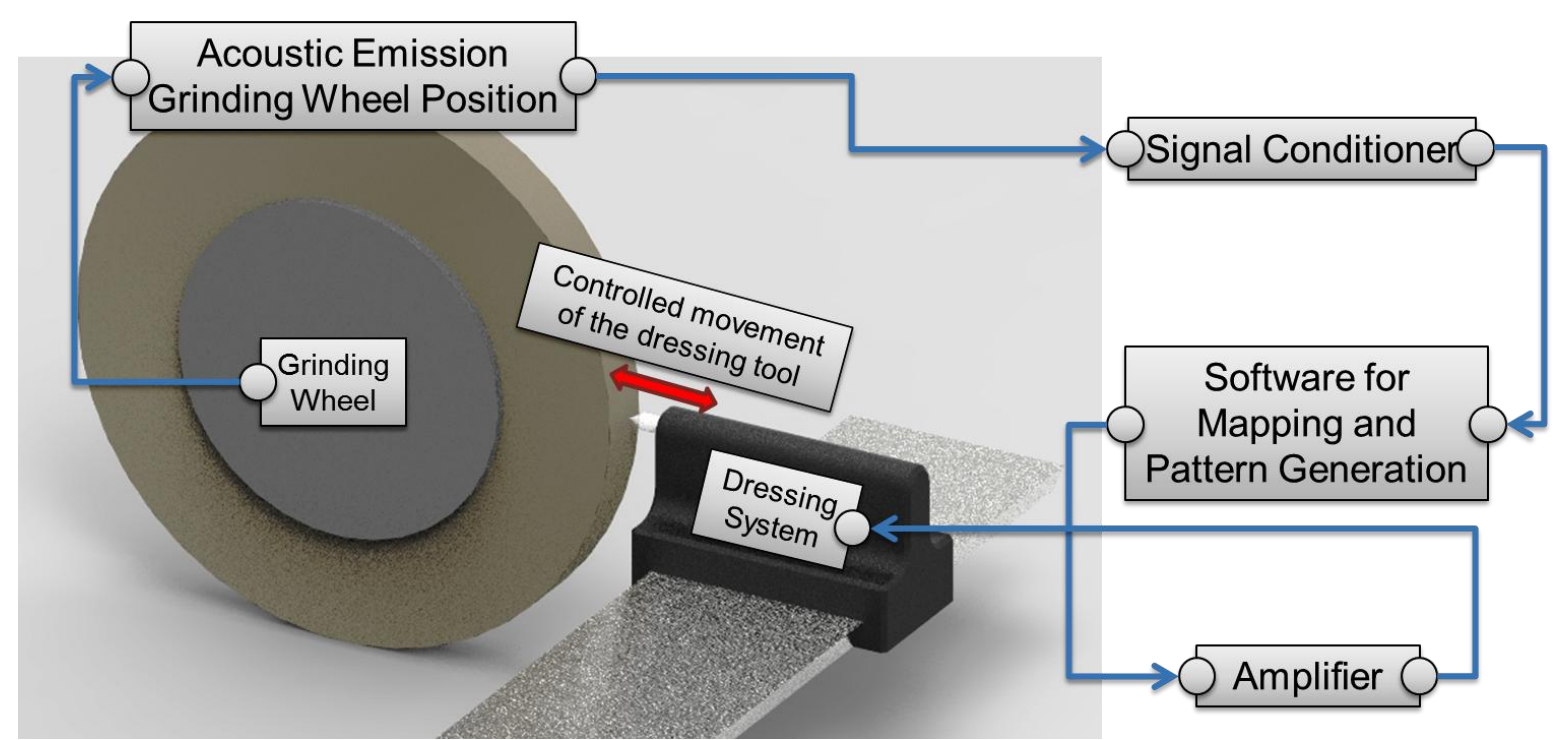

Figure 2 - Methodology for texturing via grinding, adapted [17]

\section{RESULTS}

The first step was to develop the software for texture signal controlling and monitoring. Using the patterning software, the desired texture pattern is mathematically modeled and converted into electrical signals. The model bases on wheel and part diameter ratio, dressing parameters and cutting conditions to generate signals for the actuator. In order to control the texturing, feedback sensor for wheel angular position is used. In addition, piezoelectric acoustic emission sensor is implemented for precise monitor the contact of the wheel surface with the dynamic dressing tool. The software was developed using National Instruments Labview platform.

The piezoelectric high force actuator was selected as a mechanical actuator based on the initial tests. The system also had a feedback positioning sensor integrated with the signal conditioning and amplifier, allowing nano-scale movement precision.

For the first tryouts, random textures were selected in order to evaluate the system functionality. It was selected figures to be transferred to wheel surface. The modeling software was tested to convert the desired part surface texture to fit in the wheel surface. The obtained results proved the success of the adopted methodology and encourage further developed for particular textures to be applied in crankshaft parts. Figure 3 represents some of the initial tests with the wheel surface textured. The results are based in acoustic emission (AE) grinding mapping. The analysis, developed by [19], uses RMS AE signals to monitor during cycle the contact between the grinding wheel and metal surfaces. The method combine $\mathrm{AE}$ signals and the wheel angular position to produce 3D graphs representing the contact intensity along the tool periphery. A 3D mapping graph is created using color scale to visual monitor the wheel surface. Black stands for no contact and yellow to white scale from low to high contact. Further details can be found in [19]. This methodology was used to visualize the texturing created in the wheel surface during the dressing stage. 


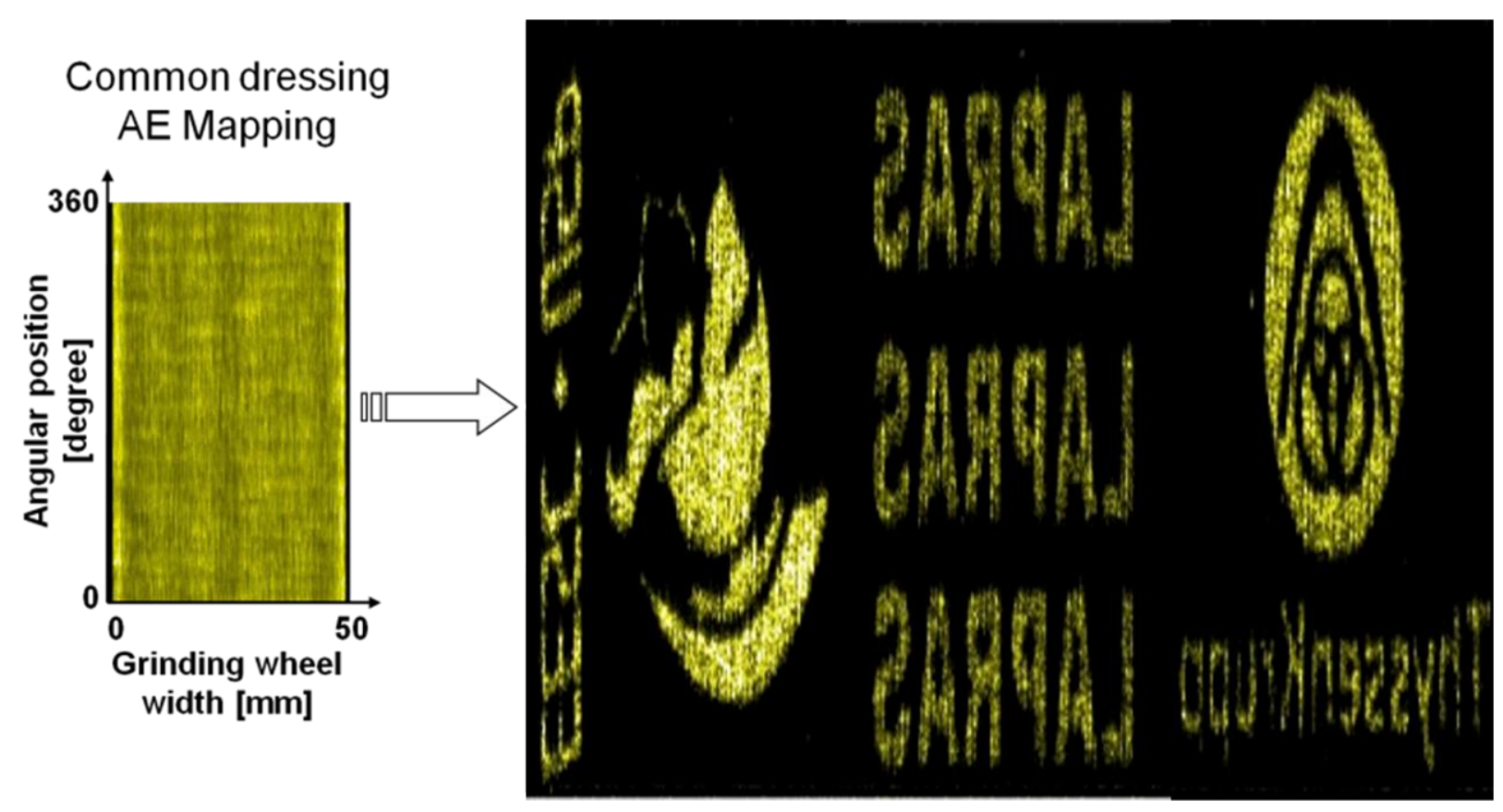

Grinding Wheel Texturing AE Mapping

Figure 3 - Random textures generated in the wheel surface during dressing

Textures with up to $15 \mu \mathrm{m}$ depth could be generated in the final part, precise based on the pictures selected. Figure 4 represents these results. The 3D AE mapping created during the dressing are used here to visualize the final part texturing. Parts pictures are was included for part surface illustration. The picture illustrates the surface generated from a texturized wheel during the cutting cycle.
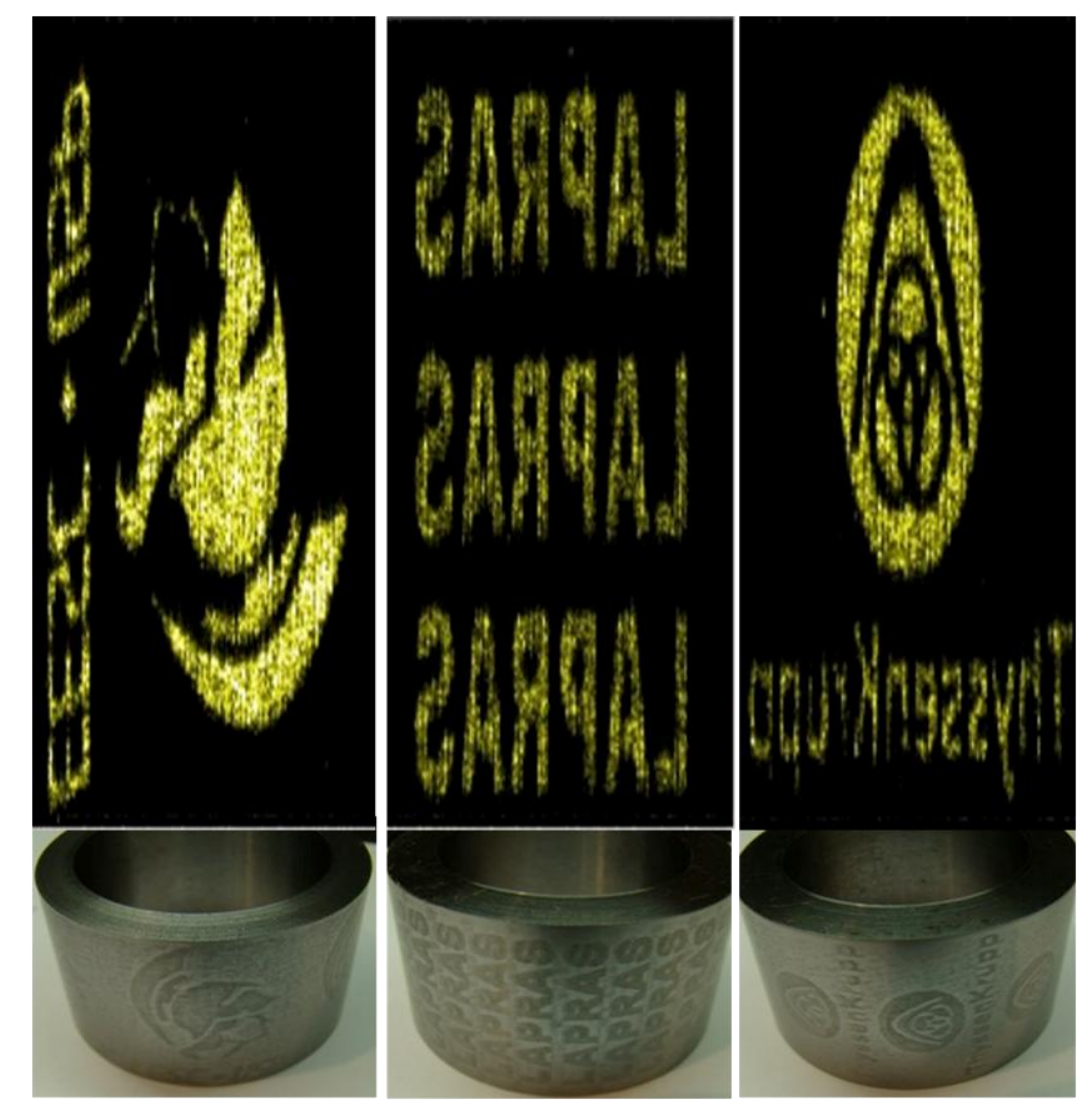
Figure 4 - Random textures transferred to the part after plunge cylindrical grinding

The next stage of development was base on literature survey to select particular textures for enhance lubrication performance, more particular, hydrodynamic bearings. Crankshaft operations efficiency in combustion engines has direct correlation with the lubrication performance. The literature review encourages the development of textures for reduction of friction and wear. Particular interest textures to be evaluated are: dimples, chevrons, chevrons channels and combined design. The initial tests were carried out using chevron channels design. Figure 5 presents these initial tryouts. A purposed chevron texture is illustrated in the left, and the 3D AE mapping created during the dressing for generate the texture in the wheel in presented in the middle. On the left, the result after plunge cylindrical grinding in the part surface is visually enhanced using red marker for the chevrons textures.

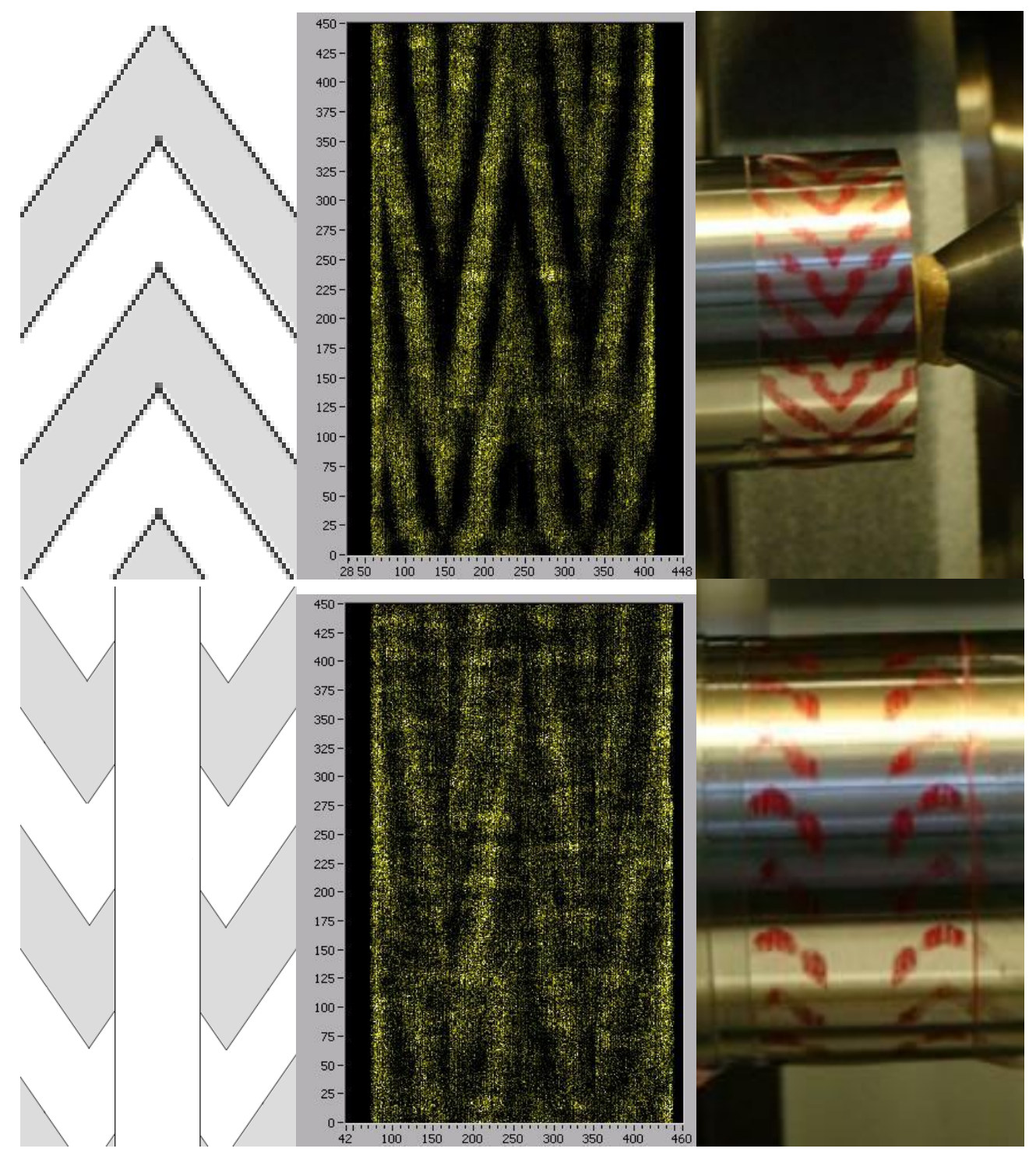

Figure 5 - Textures generated for surface functionalization in hydrodynamic bearings

For the evaluation of the surface textures performance, a test rig was developed to allow inservice performance evaluation testing patterned shafts in a hydrodynamic bearing setup. The test field is a partnership development between the Laboratory of Dynamics and the Laboratory for Advanced Process and Sustainability, University of São Paulo - USP, School 
of Engineering - São Carlos-EESC. The parameters for evaluation are: load capacity, dynamic and thermal stabilities, shaft linear displacement; maximum operating speed, among other relevant parameters to be determined. Figure 6 represents the test-field assembly and its major components.

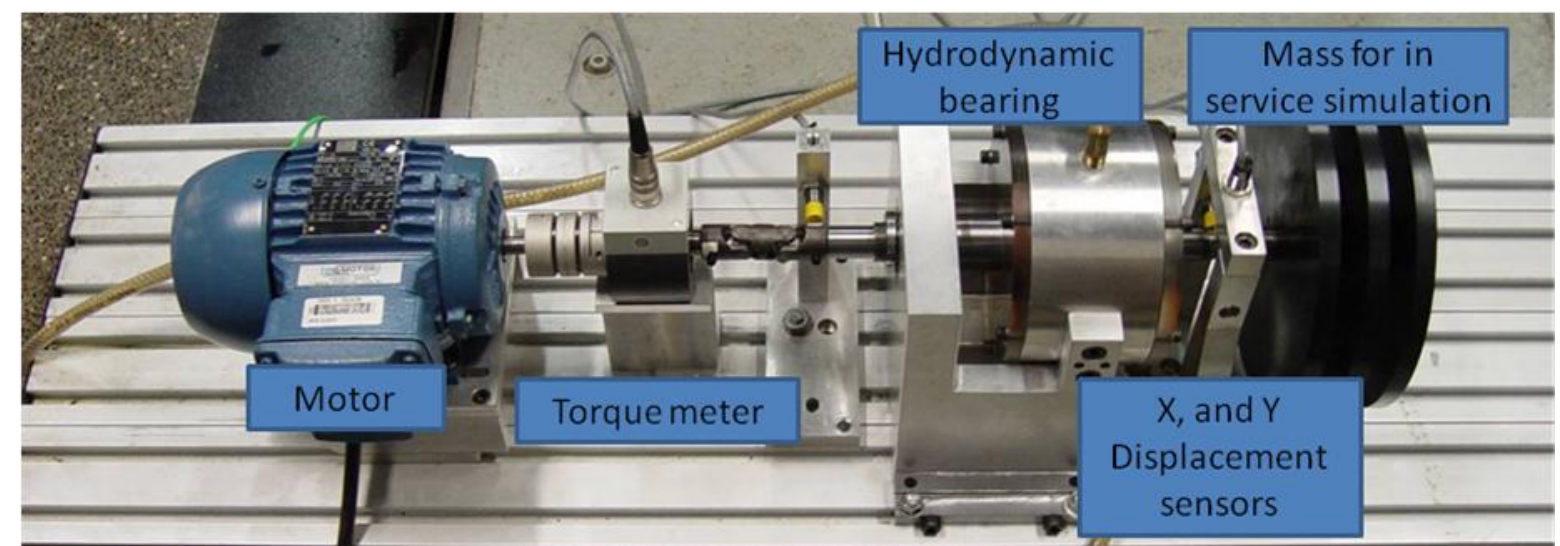

Figure 6 - Test field for hydrodynamic bearings in-service evaluation

\section{CONCLUSIONS}

The main conclusions of this research are:

- The adopted methodology for surface functionalization was experimentally proved.

- Comparable to others available process, (lases texturing, etching and burnishing), the production of patterns by grinding represents a promising option for industrial application.

- Minor machine modifications are required in the grinding machine to implement the process. For crankshaft grinding, no new machine equipment is required (such as a laser beam, when compared to the traditional approach). The shaft surface and the process high quality were preserved, adding the texture without need of additional finishing process.

- .Complementary tests will be performed for the final production of textures in crankshaft samples. The surface selected will be based on the results obtained from the test field. Final texturized crankshaft will be than evaluated in a controlled combustion engine run test. It is expected around $20 \%$ of fuel consumption reduction.

\section{ACKNOWLEDGMENTS}

The authors would like to thanks the for all the support during the project. The ThyssenKrupp Metalúrgica Campo Limpo Ltda. Company, particularly, Mr. Luis Galli - R\&D Manager and Mr. Robson Cruz - R\&D Group Leader. Also Prof. Rodrigo Nicoletti, from the Dynamis Laboratory of the School of Engineering - São Carlos-EESC, for the partnership developing the hydrodynamic bearing test field.

\section{REFERENCES}


[1] YANG, Christopher et al. Meeting an 80\% reduction in greenhouse gas emissions from transportation by 2050: A case study in California. Transportation Research Part D: Transport and Environment v. 14, n. 3, p. 147-156, 2009.

[2] ZACHARIADIS, Theodoros. On the baseline evolution of automobile fuel economy in Europe. Energy Policy v. 34, n. 14, p. 1773-1785 , 2006.0301-4215.

[3] HUO, Hong et al. Fuel consumption rates of passenger cars in China: Labels versus realworld. Energy Policy v. 39, n. 11, p. 7130-7135, 2011.

[4] ECKERT, Jony Javorski et al. Vehicle Gear Shifting Co-Simulation to Optimize Performance and Fuel Consumption in the Brazilian Standard Urban Driving Cycle. Blucher Engineering Proceedings v. 1, n. 2, p. 615-631, 2014.

[5] ROMM, Joseph. The car and fuel of the future. Energy Policy v. 34, n. 17, p. 2609-2614, 2006.

[6] LEDUC, Guillaume et al. How can our cars become less polluting? An assessment of the environmental improvement potential of cars. Transport Policy v. 17, n. 6, p. 409-419, 2010.

[7] HOLMBERG, Kenneth; ANDERSSON, Peter; ERDEMIR, Ali. Global energy consumption due to friction in passenger cars. Tribology International v. 47, p. 221-234, 2012.

[8] TUNG, Simon C.; MCMILLAN, Michael L. Automotive tribology overview of current advances and challenges for the future. Tribology International v. 37, n. 7, p. 517-536, 2004.

[9] MERLO, Alberto Maria. The contribution of surface engineering to the product performance in the automotive industry. Surface and Coatings Technology v. $174-175$, p. 21-26, 2003.

[10] JAMBOR, Arno; BEYER, Matthias. New cars - new materials. Materials \& Design v. 18, n. 4-6, p. 203-209, 1997.

[11] BRUZZONE, A. a G et al. Advances in engineered surfaces for functional performance. CIRP Annals - Manufacturing Technology v. 57, n. 2, p. 750-769 , 2008.

[12] NEVILLE, A. et al. Compatibility between tribological surfaces and lubricant additivesHow friction and wear reduction can be controlled by surface/lube synergies. Tribology International v. 40, n. 10-12 SPEC. ISS., p. 1680-1695 , 2007.

[13] FUNATANI, K.; KUROSAWA, K. Improved engine wear performance via use of Nickel Ceraic Composite Coatings (NCC coat) .Metal Matric Composites. [S.1: s.n.]. , 1994.

[14] GRABON, Wieslaw et al. Improving tribological behaviour of piston ring-cylinder liner frictional pair by liner surface texturing. Tribology International v. 61, p. 102-108, 2013.

[15] ETSION, I. Improving tribological performance of mechanical components by laser surface texturing. Tribology Letters v. 17, n. 4, p. 733-737, 2004.

[16] BORGHI, A. et al. Tribological effects of surface texturing on nitriding steel for highperformance engine applications. Wear v. 265, n. 7-8, p. 1046-1051, 2008.

[17] OLIVEIRA, J. F G; BOTTENE, A. C.; FRANÇA, T. V. A novel dressing technique for texturing of ground surfaces. CIRP Annals - Manufacturing Technology v. 59, n. 1, p. 361$364,2010$.

[18] SILVA, Eraldo Jannone Da et al. Strategies for production of parts textured by grinding using patterned wheels. CIRP Annals - Manufacturing Technology v. 62, n. 1, p. 355-358 , 2013.

[19] DE OLIVEIRA, J.F. Gomes; DORNFELD, D.a. Application of AE Contact Sensing in Reliable Grinding Monitoring. CIRP Annals - Manufacturing Technology v. 50, n. 1, p. 217-220, 2001. 